\title{
CHARGES POLÍTICAS NA PANDEMIA DE COVID-19: DISCURSOS PARA PENSAR E DISCUTIR A CONDIÇÃO
} HUMANA

\author{
Political cartoons in the COVID-19 pandemic: speeches to think and discuss the human \\ condition
}

\author{
Diana Siqueira Liberatti \\ Mestranda no Programa de Pós-Graduação \\ Interdisciplinar em Estudos da Condição Humana \\ Universidade Federal de São Carlos, Sorocaba, Brasil \\ diana.liberatti@estudante.ufscar.br \\ https://orcid.org/0000-0003-4559-153X \\ Márcio Antonio Gatti \\ Doutor em Linguística \\ Professor adjunto, \\ Universidade Federal de São Carlos \\ Sorocaba, Brasil \\ maggatti@ufscar.br

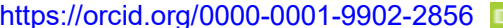

\section{RESUMO}

A lista completa com informações dos autores está no final do artigo

O presente trabalho tem como tema principal a abordagem de textos que produzem sentidos sobre a condição humana na contemporaneidade, mais especificamente durante a Pandemia da Covid-19, investigando como a linguagem enquanto discurso pode colaborar na constituição do sujeito contemporâneo. O gênero discursivo elencado foi a charge da cartunista brasileira Laerte, veiculada em mídias sociais (Instagram). Para isso, o recorte para análise foi realizado a partir do corpus coletado no primeiro trimestre do isolamento social imposto pelo período de quarentena, compreendido entre os meses de março e maio de 2020. A partir de uma perspectiva interdisciplinar que abarca os preceitos da Análise do Discurso de linha francesa e questões pertinentes às disciplinas da área de humanidades, com contribuições teóricas de Maingueneau (2007), Appadurai (2019), Orlandi (2007), Romualdo (2000), entre outros, nos debruçamos sobre o objeto de análise, investigando sua relação com a materialidade histórica, assim como o quanto foi por ela afetado. Ao olhar para os discursos e suas condições de produção, e propor uma análise, verificamos que as charges podem existir com múltiplas funções, desde a expressão ideológica até a denúncia social. Nesse sentido, elas constituem-se enquanto possibilidades de potência para a discussão da condição humana na contemporaneidade, e ao final deste processo, esperamos compreender as relações estabelecidas entre os discursos e os sujeitos, assim como qual a dimensão da relação que a materialidade sócio-histórica incide nesta produção.

PALAVRAS-CHAVE: Charge. Discurso. Produção de sentidos. Condição Humana. Contemporaneidade.

\section{ABSTRACT}

This article has as its main theme the approach of texts that produce meanings about the human condition in contemporaneity, more specifically during the Covid-19 Pandemic, investigating how language as discourse can collaborate in the constitution of the contemporary subject. The discursive genre listed was the political cartoon by the Brazilian cartoonist Laerte, aired on social media (Instagram). For this, the clipping for analysis was carried out from the corpus collected in the first quarter of the social isolation imposed by the quarantine period, between the months of March and May 2020. From an interdisciplinary perspective that encompasses the precepts of the French Discourse Analysis and issues relevant to the discipline of the humanities, with theoretical contributions by Maingueneau (2007), Appadurai (2019), Orlandi (2007), Romualdo (2000), among others, we focused on the object of analysis, investigating its relation to historical materiality, as well as how much it was affected by it. By looking at the discourses and their conditions of production, and proposing an analysis, we find that political cartoon can exist with multiple functions, from ideological expression to social denunciation. In this sense, they constitute potential possibilities for the discussion of the human condition in contemporaneity, and at the end of this process, we expect to understand the relationships established between the discourses and the subjects, as well as the dimension of the relationship the socio-historical materiality focuses on this production.

KEYWORDS: Political Cartoon. Discourse. Production of meanings. Human Condition. Contemporaneity. 


\section{INTRODUÇÃO}

Ao pensarmos nos eventos que constituem a história do ser humano distantes do momento em que aconteceram, tal qual quando estamos nos bancos escolares e somos apresentados aos manuais didáticos, as informações ali contidas nos parecem muito longínquas e abstratas. Mesmo sendo difíceis e desumanas, se pensarmos no Holocausto do século $X X$ ou na escravidão do povo negro nos séculos $X V I$ até o $X I X$, por exemplo, o discurso utilizado é generalista e superficial. Salvo algumas ocasiões em que o profissional envolvido traz para o processo a humanização nos dados, aquilo tudo nos parece distante e impossível de se repetir. No entanto, é imprescindível que consigamos vislumbrar, ler e interpretar os fatos, relacionando-os com outras materialidades históricas, a fim de verificarmos como funcionam determinados padrões de comportamento, regimes de governo, ideologias e se estão se perpetuando com outras 'roupagens'.

Já quando estamos envoltos no contexto, no "olho do furacão" como diz a expressão popular, é muito mais difícil fazer esta leitura histórica sem nos implicarmos, uma vez que somos afetados pelos acontecimentos e, ideologicamente, nos posicionamos em relação a eles. Assim, é impossível dizer que a língua é neutra e não carrega em si subjetividades advindas, produzidas e performadas pelos sujeitos que a materializam, uma vez que ela os atravessa em sua existência. Nesse sentido, é importante considerarmos que, para vivermos em sociedade é necessário nos comunicarmos, e, ao fazermos isso, consequentemente refletimos nossos valores e experiências, assim como somos refletidos pelas experiências dos Outros, uma vez que estamos pensando a língua enquanto discurso.

Nesta concepção, é importante salientar que o discurso se constitui a partir da materialidade histórico-ideológica na qual foi produzido, pois o sujeito é por ela afetado e provocado, e assim os diálogos vão estabelecendo relações com discursos anteriores. Neste sentido, a Pandemia de Covid-19 surge como um contexto que nos afeta e nos constitui, fazendo-nos refletir acerca da condição humana na contemporaneidade, mais especificamente nesta situação extrema.

Para tornar esta discussão mais concreta, nos valeremos de quatro charges produzidas pela cartunista brasileira Laerte, e veiculadas em um perfil autorizado no Instagram, intitulado @laertegenial, no primeiro trimestre do isolamento social imposto pela Pandemia da Covid-19, no Brasil. 
O objetivo é procurar nos textos elencados relações com sua materialidade históricoideológica, apontando como muitos dos desdobramentos vivenciados hoje são oriundos das práticas e posturas políticas assumidas em nosso país. Além disso, vale investigar como as charges apontadas se comportam, se exploram mais sua característica crítica ou caricatural, ou tratam de aspectos do cotidiano.

Para tanto, nos valeremos de alguns pressupostos da área da Linguística, como a Análise do Discurso de linha francesa, mas também de referências interdisciplinares na área de Ciências Humanas. Esta "parceria" nos possibilita expectativas distintas, além de colaborar enormemente na interpretação e análise dos textos elencados para o corpus, e consequentemente, para as relações do interdiscurso.

\section{DA LÍNGUA PARA O DISCURSO: UMA CONDIÇÃO PARA EXISTIR ENQUANTO HUMANO?}

Se pensarmos na definição de discurso tal qual o citamos na introdução, veremos que língua e discurso não são a mesma coisa, mas que este engloba aquela. Ao explorarmos as definições e abordagens, seja pela Análise do Discurso de linha francesa, seja por Bakhtin ou Foucault, apesar de algumas diferenças entre elas, veremos que todas têm em comum o fato de trazer para o discurso a condição de abranger uma série de enunciados, ou textos, e que estes, de maneira geral, estarão envolvidos com as condições de produção e circulação. Assim, podemos nos valer da definição de Maingueneau em Gêneses dos Discursos (2007), ao postular que "entenderemos como "discurso" uma dispersão de textos cujo modo de inscrição histórica permite definir como um espaço de regularidades enunciativas" (2007, p.15). Ao iniciar sua abordagem sobre o tema, o autor resgata a definição de Foucault para colaborar na explanação: "chamaremos discurso um conjunto de enunciados na medida em que se apoiem na mesma formação discursiva... ele é constituído de um número limitado de enunciados para os quais podemos definir um conjunto de condições de existência". (MAINGUENEAU, 2007, p. 20).

Nesse sentido, vemos que, embora um discurso apresente uma série de enunciados, ao ser apresentado para sujeitos de épocas diferentes, condições sociais distintas, com crenças díspares, podem ser também entendidos de maneiras diferentes, pois a conjuntura dada influencia na produção desses sentidos, assim como a retomada de discursos anteriores e os valores em circulação que nos atravessam. Seria ilusão de nossa 
parte imaginarmos que somos totalmente 'donos' de nossos dizeres, pois como já afirmava Foucault (1999) em A ordem do discurso "no momento da fala uma voz sem nome me precedia há muito tempo" (p. 05). A respeito deste fato, é importante pensarmos nos pressupostos da Análise do Discurso de linha francesa sobre o processo de assujeitamento aos discursos e ideologias aos quais estamos submetidos. Orlandi (2007, online) afirma que:

não há sujeito nem sentido sem o assujeitamento à língua. Quando nascemos não inventamos uma língua, entramos no processo discursivo que já está instalado na sociedade e desse modo nos submetemos à língua subjetivando-nos. (...) Quando dizemos que o sujeito, para se constituir, deve submeter-se à língua, ao simbólico, não estamos dizendo que somos pegos pela língua enquanto sistema formal, mas sim pelo jogo da língua na história, na produção de sentidos. (...) O sujeito se submete à língua(gem) mergulhado em sua experiência de mundo e determinado pela injunção a dar sentido, a significar(se) - em um gesto, um movimento sóciohistoricamente situado em que se reflete sua interpelação pela ideologia.

Se nos "significamos pela linguagem" e toda a materialidade a atravessa, enquanto discurso, é nítido que os sujeitos se manifestam de maneiras diferentes, assim como em proporções e espaços também distintos. Nesse sentido, é importante saber identificar quais são os sujeitos que se manifestam pela linguagem e ocupam estes espaços, e quais são aqueles invisibilizados pela dinâmica existente na vida em sociedade. A partir dessa premissa, é fundamental que pensemos no "não dizer" - ou silêncio: ele é também um dizer ou podemos afirmar que é o silenciamento e a ocupação pela presença da linguagem? Além disso, é imprescindível e urgente uma reflexão zelosa a respeito do que nossos discursos dizem a respeito da nossa "humanidade", da nossa condição de ser social, estar no mundo e nos relacionarmos com os outros, uma vez que ele é a própria condição de existirmos socialmente.

Dessa maneira, podemos pensar que os discursos serão percebidos de maneiras múltiplas pelos diferentes sujeitos, e, consequentemente, produzirão diferentes subjetividades, de acordo com a materialidade na qual estão circunscritos. Considerandose que o momento histórico pelo qual passamos atualmente, a saber, a pandemia de COVID-191, é um evento de proporção global e catastrófico, é fundamental que

${ }^{1}$ Pandemia de COVID-19: fenômeno causado pela proliferação do vírus SARS-CoV-2, de forma global. Com início na China, mais especificamente na cidade de Wuhan, em dezembro de 2019, a doença causada pelo coronavírus (como é popularmente conhecido), logo expandiu-se para outros continentes (América do Norte em 15/01/2020, e Europa em 22/01/2020). Apresentando índice de transmissão muito elevado, a pandemia exigiu medidas restritivas na circulação da população, e os 
investiguemos como o sujeito contemporâneo está sendo interpelado pelos discursos sobre esta crise sanitária. Além disso, faz-se necessário examinar quais são as condições sociais e ideológicas que colaboram e possibilitam a constituição do sujeito nesse cenário, uma vez que, apesar da crise ser global, ela não se inscreve na história da mesma maneira para todos.

$\mathrm{E}$, diante desses aspectos, a charge surge como uma possibilidade de discurso a ser analisado neste momento histórico, investigando-se sua relação com os sujeitos contemporâneos.

\section{A PANDEMIA DE COVID-19: UMA MATERIALIDADE HISTÓRICA VORAZ}

Caracterizada como uma crise sanitária, a Pandemia de Covid-19 logo se evidenciou também em uma crise com outras facetas: ideológica, social, financeira, política, e, sobretudo, humana. Em cada país foram notadas as suas especificidades, em maior ou menor evidência, de acordo com as características do lugar onde passava. González (2020) discorre sobre esta fragilidade, a qual nos atinge enquanto corpos biológicos, uma vez que o vírus atinge as vidas sem fazer restrição (aqui fazendo menção à discussão entabulada por Judith Butler ${ }^{2}$ ), mas também em outros âmbitos. Ele afirma que "A fragilidade biológica também atualiza uma de ordem ontológica"3 (2020, p.140), e pontua algumas mudanças que se fizeram necessárias, de ordem social, financeira, entre outras, como por exemplo a suspensão de projetos e o isolamento social.

$E$, ao chegar ao Brasil, encontrou terreno fértil para crescer em cada uma das suas particularidades. Envolvido em uma polarização ideológica muito acirrada pelas eleições de

governos decretaram o isolamento social, denominado de quarentena. A doença, muito similar a uma pneumonia, afeta o sistema respiratório, provoca insuficiência pulmonar, além de possibilidade de comprometimento dos sistemas digestivo, cardíaco e vascular (além de outras interferências ainda não catalogadas). Pode variar de sintomas leves até comprometimento sistêmico, levando ao óbito.

${ }^{2}$ BUTLER, Judith. El capitalismo tiene sus limites. Publicado inicialmente em versobooks.com e traduzido para o espanhol por Anabel Pomar para lavaca.org, em 19/03/2020. O artigo é um dos capítulos da obra coletiva Sopa de Wuhan (p.59 - 65), referenciada aqui neste artigo. Nele a autora discorre sobre a imparcialidade do aspecto biológico do vírus, mas traz à tona as questões provocadas pelas diferenças sociais que, consequentemente atuarão na crescente contaminação e proliferação da doença, como a impossibilidade de isolamento social pelas comunidades mais pobres.

${ }^{3}$ Citação no idioma original, tal qual se encontra no texto lido "La fragilidad biológica actualiza también una de orden ontológica” (2020, p.140). Tradução nossa no corpo do texto. 
2018, o povo brasileiro tem enfrentado (e ao mesmo tempo proferido se considerarmos a totalidade da população) a intensificação dos discursos intitulados de ódio, que são credibilizados pelas manifestações do atual governo. Empossado em 01/01/2019, o atual presidente da república, Jair Messias Bolsonaro, tem apresentado um discurso de intolerância contra as minorias marginalizadas, como é do conhecimento público, além de uma fala agressiva e/ou pejorativa contra a comunidade LGBTQIA+, indígenas, mulheres, negros, entre outros. Com uma campanha eleitoral pautada na luta contra a corrupção, o atual governo ganhou a confiança de milhares de brasileiros descontentes com os escândalos de corrupção que vinham assolando o nosso país, além, é claro, de potencializar seu séquito de seguidores, credibilizando discursos de ódio, de intolerância, de defesa aos empresários, às igrejas protestantes, e à família tradicional. Appadurai (2019) corrobora este fato ao discorrer sobre a ascensão crescente de líderes populistas nos últimos tempos, ao redor do globo. Para ele, "os líderes que ascenderam nos novos movimentos populistas têm estilos tipicamente xenófobos, patriarcais e autoritários", e "os seguidores talvez partilhem de algumas dessas propensões, mas também estão assustados, zangados e ressentidos com o que a sociedade em que vivem fez por e com eles" e, nesse sentido, é um processo que parece claro e natural "que esses perfis se encontrem, principalmente nas eleições" (APPADURAI, 2019, p. 20).

A crise que tensionava o país já era grande quando a pandemia chegou em território brasileiro no final de fevereiro de 2020. Com as orientações da OMS - Organização Mundial de Saúde sobre a necessidade da quarentena, em 15/03/2020, a Pandemia da Covid-19 no Brasil passou a ser muito mais uma crise política do que sanitária.

As fake news ${ }^{4}$, fenômeno tão presente na contemporaneidade, já eram apontadas na corrida eleitoral e passaram a ser veiculadas com muita frequência no desserviço da desinformação. Além disso, a polarização existente no campo político migrou para a temática da pandemia, de acordo com aquele que gera confiabilidade nos discursos: a ciência, a liderança política, a bancada religiosa etc. Isso pode se justificar se pensarmos que "ser significa comunicar... O homem não possui um território interior soberano, ele está

\footnotetext{
${ }^{4}$ Fake news: em tradução literal do inglês, é uma expressão que significa notícias falsas. Apropriada em nosso país, a expressão passou a ser utilizada sem tradução e, infelizmente, é um fenômeno muito presente em nosso tempo. As fake news podem ser notícias criadas de maneira falsa ou adulteradas a fim de prejudicar algo ou alguém, comprometendo sua credibilidade. A internet possibilita uma veiculação em tempo muito rápido, além de atingir um número massivo de pessoas, fato que potencializa o evento. Além disso, notícias antigas também podem ser publicadas (ou utilizadas em novas publicações), descontextualizadas, em outras situações daquelas que as originaram, possibilitando produção de sentidos diversos.
} 
inteiramente e sobre uma fronteira; olhando para o interior de si, olha nos olhos do outro ou através dos olhos do outro" (MAINGUENEAU, 2007, p. 35), e assim os sujeitos e/ou instituições representativos na comunidade credibilizam os discursos com os quais nos identificamos e, consequentemente, acreditamos e passamos adiante.

Maingueneau (2020) nos chama a atenção para alguns tipos de discurso que a pandemia de Covid-19 possibilitou na investigação ainda inicial da doença: o do perito, aquele que é científico (pensando nos profissionais da saúde e no corpo de pesquisa); o do governo, que deve tomar decisões, mas baseadas nas orientações dadas pelos peritos; o do sujeito comum, que não é contemplado nesse momento. $E$, segundo o linguista, logo o contexto aponta a necessidade de um comitê interdisciplinar na contenção e pesquisa da crise, englobando vários profissionais: infectologistas, fisioterapeutas, pneumologistas, entre outros. E logo depois, a criação de outros comitês começa a surgir, pensando-se na administração da crise (questões de ordem social, acolhimento da população, mercado etc.). No Brasil, tivemos, desde o início, uma dificuldade grande entre alguns tipos de discurso. No primeiro momento, ela aconteceu em campos semânticos distintos, ou seja, o científico e o governamental. Posteriormente, por influência daquele antagonismo já existente, as diferenças começaram a surgir dentro deste mesmo espaço, por exemplo: medicina que apoia as decisões científicas $\mathrm{x}$ médicos que experenciam medicamentos e procedimentos sem comprovação científica, governo federal e ministro da saúde, governo federal e governos estaduais e/ou municipais, entre outros.

Orientado pelo negacionismo, o discurso apresentado pela figura presidenciável brasileira corrobora o que González (2020) apontou como "gestão da morte realizada por alguns governos" (p. 143), 'delegando' à comunidade a árdua tarefa de lutar pela vida. Em 16 de março de 2020, no início da pandemia no Brasil, o presidente apareceu sem máscara em público, para dialogar com grupo de apoiadores na entrada do Palácio do Alvorada, e afirmou categoricamente que "a crise não era para tanto, uma vez que na China tudo já estava quase acabando" (Folha de São Paulo, online, 16.03.2020). Nessa data, a contagem de vítimas pelo coronavírus no mundo já havia atingido a marca de 6.513 pessoas. ${ }^{5}$ No dia seguinte, nosso país teve a primeira morte noticiada, e seu discurso enquanto líder da nação foi uma crítica às medidas tomadas para contenção da pandemia, uma vez que, na opinião dele, "medidas tomadas por 'alguns governadores' contra o surto da doença 'vão

\footnotetext{
${ }^{5}$ Maiores informações em: https://www1.folha.uol.com.br/poder/2020/03/mesmo-apos-6513mortes-bolsonaro-diz-que-crise-do-coronavirus-nao-e-isso-tudo-que-dizem.shtml, Acesso em: 20/06/2021.
} 
prejudicar em muito a nossa economia (...) esse vírus trouxe uma certa histeria" (CNN Brasil, online, 17.03.2020) ${ }^{6}$.

A partir dessas considerações, podemos pensar sobre quais são as medidas necessárias para que um líder demonstre consideração e cuidado com a população, para que todos sintam-se minimamente seguros. Aliado a isso, é urgente que nos debrucemos sobre os discursos que nos interpelam, considerando a coerência de cada um com a postura daqueles que os veiculam: eles funcionam como manipulação, denúncia, informação? Apoiam um plano de governo?

Para problematizar estas questões que incidem diretamente na condição humana do indivíduo contemporâneo, nos dedicaremos à leitura e análise de alguns textos, de maneira concisa.

\section{CHARGE: GÊNERO DISCURSIVO E POSSIBILIDADE DE DISCUSSÃO DA SOCIEDADE}

A charge é um gênero discursivo que surpreende pela versatilidade, ao englobar várias funções em si mesma. Pilla e Quadros (2009, p. 226) afirmam que "ela pode ser considerada uma prática discursiva situada no cosmo das relações entre o linguístico e o histórico-social", pois sua materialidade está intimamente ligada a um acontecimento real, advindo de uma notícia, e normalmente política. Ao escrever seu texto, o chargista, por meio da junção do texto verbal e imagético, consegue estabelecer uma sequência narrativa, elaborar uma crítica, e na maioria das vezes, envolver humor neste processo, provocando o riso.

De caráter originalmente caricatural, a charge está intimamente ligada ao universo dos textos jornalísticos. Romualdo (2000) elabora um resgate histórico sobre o gênero em questão e aponta sua existência desde o final do século XIX. Vale lembrar que nos primórdios ela estava muito ligada à questão da imagem e da caricatura e não apresentava as mesmas características atuais, mas a essência da crítica já era clara. Em sua obra, ele ainda relata a existência do texto chargístico muito integrado ao jornal escrito, uma vez que sua pesquisa foi realizada na década de 1990, e seu recorte enfocava este espaço. Segundo ele, algumas delas inclusive deveriam ser escritas para dialogar com os demais

\footnotetext{
${ }^{6}$ Maiores informações em: https://www.cnnbrasil.com.br/politica/2020/03/17/bolsonaro-volta-afalar-em-histeria-e-diz-que-medidas-contra-coronavirus-afetam, acesso em: 20/06/2021.
} 
textos do periódico. Pilla e Quadros (2009, p. 227) também evidenciam o fato, ao afirmar que a charge está "estreitamente relacionada à prática jornalística", e nesse sentido "é um gênero de discurso que não está isento de influências sócio-históricas".

No entanto, os gêneros do discurso têm passado por mudanças que incidem em seu modo de existir, como o espaço de veiculação por exemplo, visto que são produzidos a partir das necessidades humanas. Nesse sentido, as charges ocuparam o novo espaço criado a partir da era digital, infiltrando-se e conquistando cada vez mais espaço nesta veiculação. As possibilidades são várias, tais como os blogs individuais e/ou coletivos, revistas eletrônicas e páginas pessoais, por meio das redes sociais - como o Facebook, Instagram, Twitter, entre outras.

Já no espaço jornalístico físico, a charge era de responsabilidade de seu produtor, pois é um texto que apresenta caráter polêmico e crítico - às vezes muito mais intenso que as crônicas e artigos de opinião, por exemplo. Assim, o texto chargístico é assinado por aquele que a produz, e, nesse contexto da era digital, as páginas pessoais possibilitam uma divulgação daqueles profissionais/autores que não estão ligados a alguma instituição, como os jornais por exemplo. E, nesse cenário, o espaço virtual possibilita maior visibilidade ao gênero, assim como possibilidades de interação com o público leitor. Uma vez que "o discurso de humor gráfico é uma narrativa eloquente que, ao usar recursos expressivos, possibilita uma leitura para além dos elementos superficiais do texto", inclusive auxiliando “o leitor na construção de novos e outros significados” (PILLA E QUADROS, 2009, p. 226), é importante apontar que a charge veiculada eletronicamente se constitui um instrumento para análise de produção de sentidos com potencial considerável, visto que as mídias sociais ocupam hoje um importante espaço na vida cotidiana. $E$, na medida que "o discurso da charge desvela o cotidiano da sociedade, valores, experiências, fraquezas, misérias e grandezas marcadamente humanas", elas podem ser consideradas "potencialmente decisivas no processo de construção e veiculação de ideologias" (PILLA E QUADROS, 2009, p. 227).

Considerando-se todas as questões acima expostas sobre sua definição, contextualização, produção e veiculação, a charge foi aqui escolhida como objeto de análise. Para tanto, nos utilizaremos de charges da cartunista Laerte, coletadas no perfil intitulado@laertegenial, autorizado pela artista no Instagram, e divulgadas no primeiro trimestre do isolamento social da pandemia da Covid-19 no Brasil. 


\subsection{Charges da Laerte: denúncia e provocação para o sujeito}

Laerte Coutinho, mais conhecida somente como Laerte, é uma cartunista, ilustradora e roteirista brasileira, nascida em 1951. Em sua trajetória profissional esteve vinculada a revistas e jornais de grande circulação e prestígio, tais como O Pasquim, Correio Brasiliense, Folha de São Paulo, Chiclete com Banana. Atuou como roteirista na Rede Globo de Televisão, e trabalhou em parceria com grandes nomes no ramo, como os cartunistas Angeli e Glauco.

Enquanto suas produções das décadas de 1970 e 1980 estavam muito ligadas a questões políticas, as criações dos anos 2000 começaram a contemplar temáticas que refletiam sua trajetória pessoal, ou seja, sua reflexão sobre identidade de gênero. Assim, mais envolvida com as demandas de gênero, sexualidade e direitos humanos, a cartunista explora temáticas importantes para a existência humana.

Para este trabalho, foram elencados os discursos chargísticos que dialogam com as inquietações apontadas anteriormente. Em primeiro lugar, retomaremos a questão do negacionismo no discurso do presidente Jair M. Bolsonaro, o qual reverbera tanto a identificação daqueles que o apoiam, quanto aqueles que já apresentavam este posicionamento e se sentiram credibilizados pela figura representativa do líder governamental.

A primeira charge, veiculada em 15.03.2020, e depois repetida em 22.05.2020, segue abaixo:

\section{Charge 01}

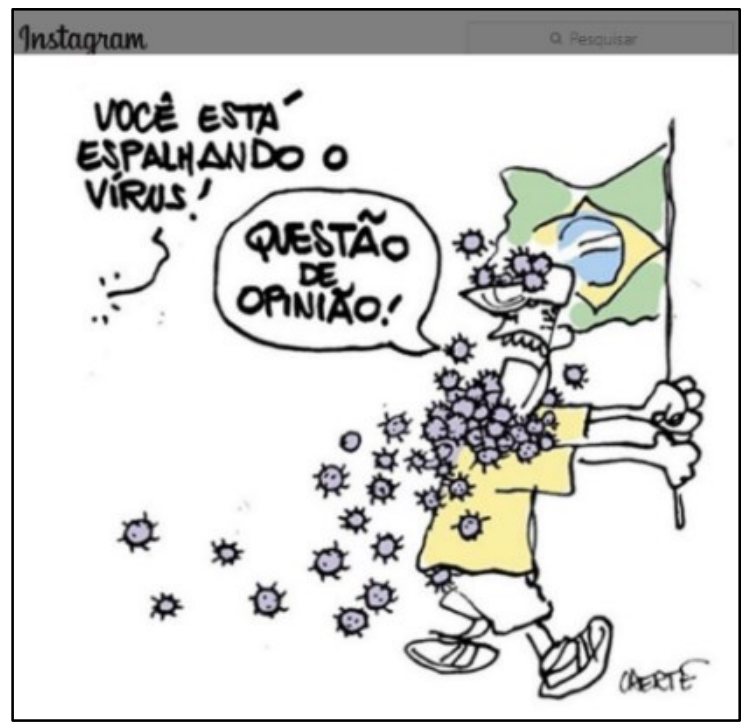

Fonte: perfil do Instagram @laerte genial

Disponível em: https://www.instagram.com/p/B9xqqwDgDdn/, Acesso em: 10/06/2020. 
Ela apresenta um signo imagético de um homem vestido com uma camiseta amarela e empunhando a bandeira brasileira. Ele não usa máscara e, aparentemente, pela presença da bandeira empunhada, supõe-se que ele esteja em via pública. Com a imagem de muitos coronavírus em si, caindo durante a sua passagem e sugerindo a contaminação do espaço, o signo verbal indica duas falas em polos distintos. A primeira, em tom acusatório (ou seria alarmado?) aponta: "Você está espalhando o vírus!", ao que é prontamente respondida pelo seu interlocutor: "Questão de opinião!". A expressão facial do sujeito presente insinua seu descontentamento com a fala do outro.

A charge resgata um diálogo urgente sobre a "questão de opinião" e "sua opinião", fato que tem tensionado as relações em tempos pandêmicos. Os discursos veiculados desde o início desta situação tem mostrado ausência de coesão e unidade entre as lideranças políticas e as pesquisas científicas e os profissionais que fazem ciência em prol de uma "saída" para a crise instituída - seja a vacina, a profilaxia dos contaminados, a prevenção da comunidade em geral. E no texto exposto isso é claramente visível, uma vez que vemos o não cumprimento de medidas instituídas em Decretos Governamentais, normalmente na instância estadual, tais como: quarentena, ou seja, o isolamento social; o uso de máscaras em espaços públicos, e estabelecimentos compartilhados, como comércio, ambiente de trabalho, entre outros; e a higienização constante das mãos, seja com água e sabão ou com álcool em gel.

$\mathrm{Na}$ data da publicação da charge aconteceu um ato pró-governo, e o presidente esteve presente ${ }^{7}$. Assim, é possível afirmar que o texto chargístico surge como uma denúncia na relação dinâmica com o sujeito. Vemos assim, tal qual Appadurai (2019) postula ao dissertar sobre como se estabeleceu o contexto da "sensação de cansaço da democracia”, que aqui também existe a necessidade de identificar-se. Segundo o autor,

A expansão da internet e das mídias sociais a setores crescentes da população e a acessibilidade da busca de pares, construção identitária, propaganda e mobilização baseadas na web criaram a ilusão perigosa de que todos podemos encontrar semelhantes, aliados, amigos, colaboradores, convertidos e colegas, independentemente de quem somos e do que desejamos" (APPADURAI, 2019, p.28).

Essa necessidade de nos vermos no outro e/ou de pertencimento a um grupo é alimentada pela postura do presidente, ficando visível a ausência de pensamento coletivo

\footnotetext{
7 Maiores informações em: https://g1.globo.com/politica/noticia/2020/03/15/mesmo-com-recomendacao-demonitoramento-por-coronavirus-bolsonaro-participa-de-carro-de-ato-em-brasilia.ghtml, acesso em 25/06/2021.
} 
unificado no combate à pandemia em nosso país, mas que reflete aquela imagem idealizada. Podemos identificar, assim, uma postura de denúncia no discurso da charge.

$\mathrm{Na}$ data em que foi publicada novamente - durante o período da coleta do corpus para análise, em 22.05.2020 - a notícia em destaque na mídia era sobre o apoio do presidente ao uso do medicamento cloridrato de cloroquina, como tratamento aos infectados pelo coronavírus, mas não comprovado cientificamente, e ainda, ampliando o seu uso ${ }^{8}$. Neste dia, o Brasil contabilizou 18.859 óbitos pela doença, mas o negacionismo era evidente, assim como a postura de resistência.

A segunda charge que constitui este corpus foi publicada em 23.03.2020, pelo perfil @laertegenial, e está disponível abaixo para a leitura:

Charge 02

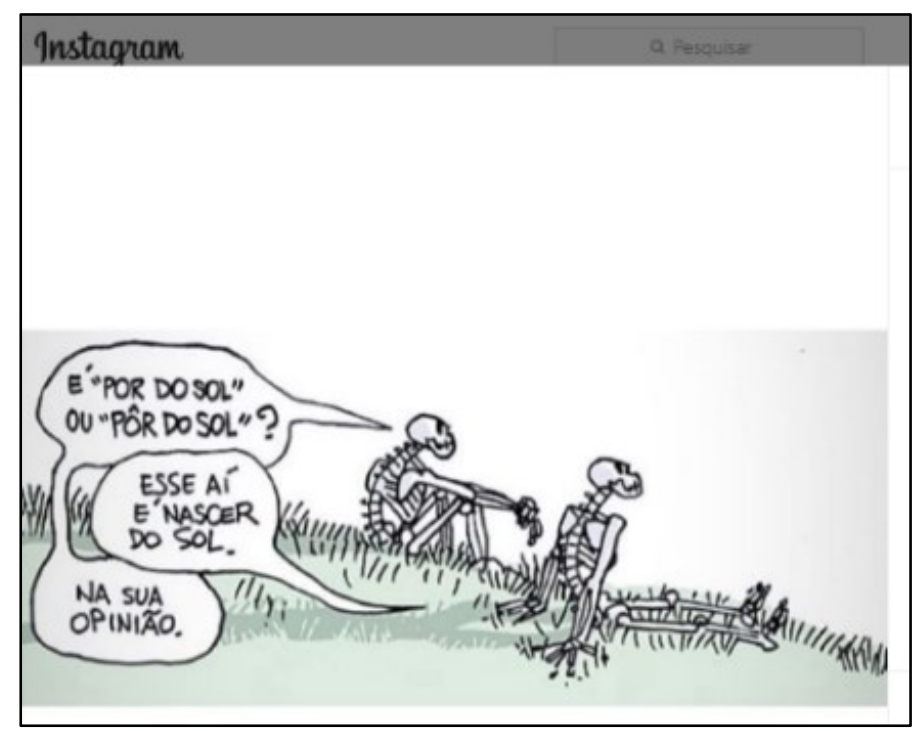

Fonte: perfil do Instagram @laerte genial

Disponível em: https://www.instagram.com/p/B-FHwKKg1Yk/, acesso em 10/06/2020.

É visível a cena de diálogo entre duas caveiras, apreciando o horizonte. As imagens, muito significativas em nossa materialidade histórica, sugerem que, mesmo acometido pela crise, o país continua a negá-la (personificando assim o substantivo abstrato país). O signo verbal aponta duas falas, também aparentemente em posições ideológicas opostas. $O$ interlocutor 01 pergunta: "É 'por do sol' ou 'pôr do sol'?"; ao que é respondido pelo interlocutor 02: "Esse aí é nascer do sol". Vemos assim que inicialmente a proposta era um

\footnotetext{
${ }^{8}$ Maiores informações em: https://www.dw.com/pt-br/as-principais-not\%C3\%ADcias-sobre-apandemia-de-coronav\%C3\%ADrus-20-05/a-53505144, acesso em: 25/06/2021.
} 
diálogo sobre questões a respeito da língua portuguesa (por exemplo: acentuação, classe das palavras), mas passa para um contexto ideológico ao passo que o seu respondente desloca totalmente o objeto de análise. Para encerrar o diálogo, temos o célebre enunciado “Na sua opinião". Os enunciados verbais corroboram uma leitura de alienação dos sujeitos, visto que a morte já os atingiu e mesmo assim, o assunto escolhido é algo do cotidiano, como se estivessem empenhados em desviar o foco da atenção dos valores e questões realmente necessários no momento.

O próximo texto do nosso corpus, publicado em 28.04.2020, é quase totalmente não verbal, exceto pela inscrição na plataforma que sustenta a imagem em destaque. Observe:

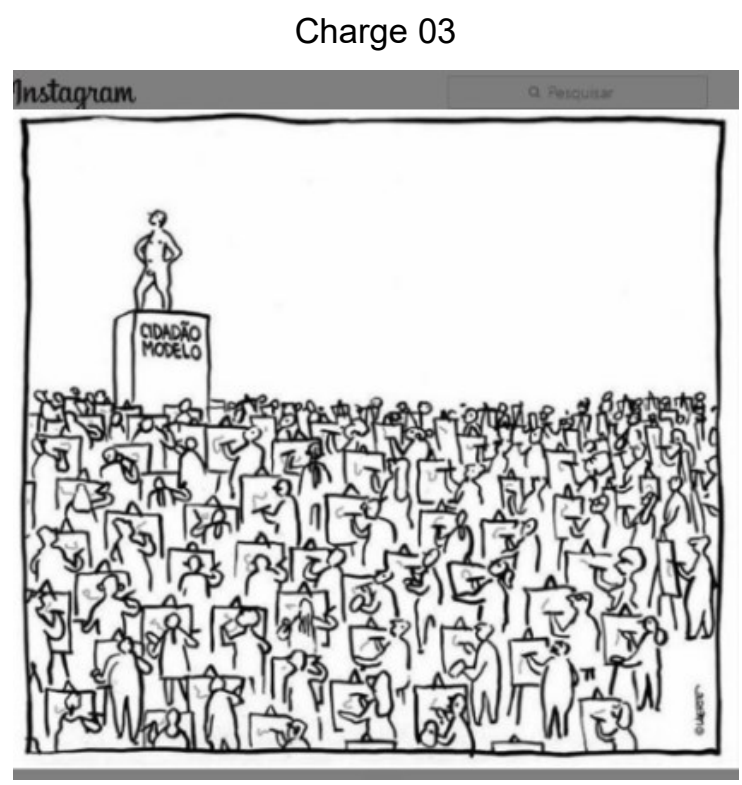

Fonte: perfil do Instagram @laerte genial

Disponível em: https://www.instagram.com/p/B_i-1MCDPbV/, acesso em 10/06/2020.

Nele vemos uma escola de desenho/pintura sendo simbolicamente representada pelas imagens. A maioria dos sujeitos retratados parece estar no mesmo nível físico exceto aquele que está em destaque-, e ocupar a posição de busca da inspiração na imagem que está acima de todos fisicamente. A inscrição no signo verbal sugere que esta supremacia é também ideológica, uma vez que a inscrição se materializa em "cidadão modelo" (Modelo de quê? Forma física, pela postura? Posição social, pelo nível superior? De comportamento, pelo porte?).

Os sujeitos representados por aqueles que 'copiam' o modelo apresentam uma expressão corporal de embevecimento. Apesar dos traços serem genéricos (as pessoas não têm muitos detalhes pela sua quantidade e tamanho em que estão representadas), é 
possível verificarmos que todos os olhares estão voltados para a imagem, todos estão compenetrados na tarefa. Não há postura díspar retratada, o que nos remete às expressões utilizadas ultimamente "moral de rebanho", "comportamento de rebanho", "ideologia de rebanho" e "postura de rebanho". Independente de qual seja a primeira palavra que compõe a expressão, a ideia que se almeja é a de que as pessoas estão seguindo, sem questionamento, um líder. Este fato se relaciona ao já abordado "discurso de valor" (figura representativa) que credibiliza ações e discursos proferidos pelos sujeitos em suas individualidades, e antes questionados.

Appadurai (2019), ao explanar o processo pelo qual temos uma incidência grande de líderes populistas no poder, aponta que há uma dificuldade muito grande em lidar com as limitações financeiras das nações (dívidas, legislações, sanções...). Sabendo que atender as promessas neste âmbito será tarefa non grata, os políticos têm investido em promover questões pertinentes ao resgate da cultura, da soberania, dos valores tradicionais. $\mathrm{O}$ autor afirma que:

Portanto, é isso que os líderes dos novos regimes populistas autoritários têm em comum: a admissão de que nenhum deles pode de fato controlar a economia de seus países, refém de investidores estrangeiros, acordos globais, finanças transnacionais, mão de obra móvel e capital de modo geral. Todos eles prometem a purificação da cultura nacional como via de poder político global. Todos são simpáticos ao capitalismo neoliberal, cada um com sua própria versão de como fazê-lo funcionar (...). Todos buscam converter poder brando em poder coercitivo. E nenhum deles tem restrições quanto a reprimir minorias e dissidentes, abafar a liberdade de expressão ou usar as leis para sufocar os oponentes. (APPADURAI, 2019, p.25)

Esta afirmação mostra algumas questões discutidas na Charge 03 , ou seja, a identificação do sujeito individual com algo que credibiliza sua fala/seu agir, tornando-o assim um coletivo, oferecendo-lhe um espaço de pertencimento, pois é uma figura que, teoricamente, deveria estar a serviço da sociedade.

Na charge 04 do nosso corpus, encontraremos uma reverberação desta temática. Publicada em 17.03.2020, ela segue abaixo para apreciação: 


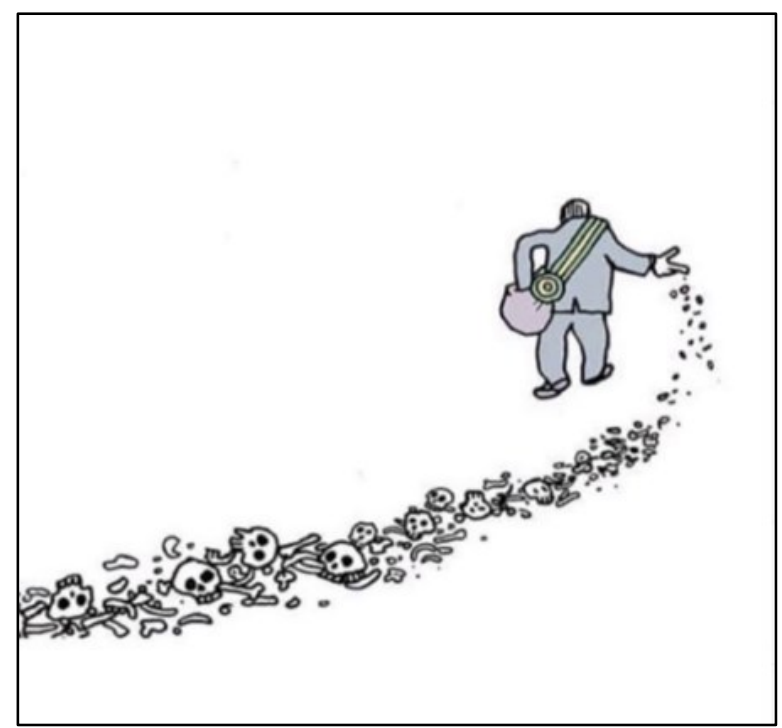

Fonte: perfil do Instagram @laerte genial

Disponível em: https://www.instagram.com/p/B929rl0A54c/, acesso em 10/06/2020.

Último texto deste recorte para análise e discussão, ele apresenta somente o signo não verbal. Nele há uma figura que, simbolicamente, nos remete ao presidente da república - vestimenta formal, com o que parece ser um terno e a faixa presidencial. A faixa, que é símbolo de nacionalidade, aqui também representa a alça transversal de uma bolsa, conhecida pelos trabalhadores do campo como 'embornal', um saco costurado em lona (ou tecido semelhante), que carregava a refeição, ou o alimento a ser distribuído aos animais, ou ainda as sementes a serem lançadas na terra - quando este processo ainda era artesanal. Aqui a representação do presidente da república aparece de costas para o leitor, caminhando e parece-nos que ele tira algo da bolsa com a mão esquerda enquanto com a mão direita vai lançando ao solo. Pela representação ao longe não nos é possível ver o que cai de sua mão, mas no caminho que vai se formando atrás dele, a imagem é de ossos e caveiras. Contrariamente à imagem do lavrador que semeia a terra com vida, a charge nos mostra a morte sendo cultivada em solo nacional, em proporção amplificada, decorrente das decisões do governo nacional. Além disso, podemos estabelecer uma intertextualidade com a narrativa infantil de João e Maria, originalmente publicada pelos Irmãos Grimm, na qual os irmãos, ao serem levados para a floresta deixam atrás de si um caminho de pedras coloridas para encontrarem o caminho de volta. Sob esta ótica, é sugestiva a ideia de que a trilha deixada pela figura presidenciável tem ao menos duas utilidades: em primeiro lugar serve de guia para aqueles que se identificam com seu discurso, com seu posicionamento. 
A seguir é possível pensarmos que a mesma trilha é suficiente para evidenciar suas ações, possibilitando investigações e denúncias.

\section{CONSIDERAÇÕES FINAIS}

Ao iniciarmos esta seção, podemos recuperar alguns dos questionamentos que foram sendo deixados ao longo do texto. Se pensarmos que somos constituídos pela língua, socialmente, e neste caminho nos manifestamos de maneiras diferentes, de acordo com algumas variáveis, é importante salientarmos que nem todos materializam seus discursos na proporção e espaço em que gostariam. Um bom exemplo disso, utilizando nosso recorte histórico, são as vidas representadas na charge 04, as quais foram silenciadas, seja pela ausência de um leito no hospital, pela falta de um aparelho respiratório, pela crise provocada pela ausência de oxigênio em Manaus, pela impossibilidade de cumprir o isolamento social. González (2020) salienta que o vírus explica nossa fragilidade biológica, mas também outras. Ele aponta que ele é

a condição e a causa do conteúdo de nossos afetos atuais: medo, tédio, solidão, descrença etc. Fomos invadidos em nosso dia a dia, porque devemos, aqueles de nós que temos esse privilégio em países com estados subsidiários, permanecer em casa. (GONZÁLEZ, 2020, p. 141) ${ }^{9}$.

Constatamos assim que há a condição imediatamente relacionada com a Covid-19, como a questão dos hospitais lotados, o caos instalado no sistema de saúde em geral, a necessidade da contenção à contaminação, com o uso de máscaras e higienização, mas também outras se manifestam indiretamente, como o poder coercitivo dos líderes, a intensificação das diferenças pelo neoliberalismo, a proliferação do discurso de ódio às minorias credibilizada pelo governo de caráter populista. $E$, de quem eram essas vozes que ficaram pelo caminho? Se pensarmos nos apontamentos realizados por Appadurai (2019) ao longo deste texto, fica visível que pertencem àqueles que são rechaçados por este discurso da intolerância (as mulheres, LGBTQIA+, indígenas e população negra).

Uma próxima pergunta seria: O que nossos discursos dizem da nossa humanidade, da nossa condição de ser social, estar no mundo e nos relacionarmos com os outros, se

9 Citação no idioma original, tal qual se encontra no texto lido: "La condición y causa de los contenidos de nuestros afectos actuales: miedo, aburrimiento, soledad, incredulidad, etc. Hemos sido invadidos en nuestra cotidianidad, porque debemos, quienes tenemos ese privilegio en los países con estados subsidiarios, permanecer en casa" (GONZÁLEZ, 2020, p. 141). Tradução nossa no corpo do texto. 
ele é a própria condição de existirmos socialmente? Muitas vezes nos esquecemos que a prática está vinculada ao discurso, uma vez que este reflete nossas crenças, nossas relações, nossas memórias. Assim sendo, não é possível desvincular um de outro, e esta constatação deveria nos assustar se analisarmos o quão desumanizados estamos nós humanos. O que define então a condição humana na relação com o outro?

Se retomarmos o texto introdutório, veremos que apesar das épocas serem diferentes, de termos muito desenvolvimento tecnológico e científico, algumas das questões mais básicas continuam se perpetuando, como a exploração dos menos favorecidos e a disputa pelo poder. Quando Hannah Arendt (2015) discorre sobre a condição humana e a banalidade do mal, muitos a condenam, mas o que ela apontava era que o mal não é um ser absoluto que nos manipula, que é abstrato e externo ao humano. Muito pelo contrário, ele faz parte da personalidade humana, juntamente com outras facetas, e muitas vezes reside nas ações mais simples e cotidianas (no entender singular de cada um). Ao transpormos a diferença de tempo, nos deparamos com notícias de superfaturamento em produtos hospitalares, por exemplo. E o que é isso senão a ação mecânica praticada por Adolf Eichmann, durante o III Reich?

Nesse sentido, as charges podem ser consideradas como possibilidades para se pensar e discutir a pandemia da Covid-19, assim como outras materialidades históricas que apontam questões importantes sobre nossa condição enquanto humanos. Elas se mostram efetivas enquanto instrumentos de engajamento, de discussão e provocação; de denúncia; e de luta, cada um à sua maneira, existindo e resistindo. E, como apontado por Maingueneau (2007, p.16), "só uma parte do dizível é acessível”, sendo necessário estarmos atentos às nuances discursivas que nos escapam e nos oprimem.

\section{REFERÊNCIAS}

APPADURAI, Arjun. Fadiga da democracia. In: A grande regressão: um debate internacional sobre os novos populismos e como enfrentá-los. Arjun Appadurai et al. Trad. de Silvia Bittencourt et al. $1^{\text {a }}$ ed. São Paulo: Estação Liberdade, 2019. (págs. 19-34).

ARENDT, Hannah. A Condição Humana. In: ARENDT, Hannah. A Condição Humana. Rio de Janeiro: Forense Universitária, 2015. (p. 01-26).

FOUCAULT, Michel. A ordem do discurso - AULA INAUGURAL NO COLLEGE DE FRANCE, PRONUNCIADA EM 2 DE DEZEMBRO DE 1970. Trad. Laura Fraga de Almeida Sampaio. $5^{a}$ ed. São Paulo: Edições Loyola, 1999. 
GONZÁLEZ, Gustavo Yañez. Fragilidad y tiranía (humana) en tiempos de pandemia. Publicado inicialmente em: ficciondelarazon.files.wordpress.com, em 26 de março, 2020. In: Sopa de Wuhan: Pensamiento Contemporáneo en Tiempos de Pandemias. $1^{\mathrm{a}}$ ed., março de 2020. Disponível em: https://ihacdigital.ufba.br/786/, acesso em: 20.04.2020. (p.139-143).

MAINGUENEAU, Dominique. Gênese dos Discursos. Trad. Sírio Possenti. Curitiba - PR: Criar Edições, 2007.

MAINGUENEAU, Dominique. A análise do discurso e a crise do Coronavírus. Live. Transmitida ao vivo em 03/06/2020. Disponível em: https://www.youtube.com/watch?v=rXzRIOUdvKk\&ab channel=Abralin, acesso em. 03/06/2020.

Ministério da Saúde. O que é a Covid-19? Publicado em 08/04/2021. Disponível em: https://www.gov.br/saude/pt-br/coronavirus/o-que-e-o-coronavirus, acesso em: 25/06/2021.

ORLANDI, Eni Pulcinelli. Violência e processos de individualização dos Sujeitos na contemporaneidade. Trabalho apresentado no CIAD-São Carlos, UFSCAR, 2007. ORLANDI, Eni Pulcinelli. A questão do assujeitamento: um caso de determinação histórica. Revista eletrônica Comciencia, publicado em 30.07.2007, UNICAMP. Disponível em: http://www.comciencia.br/comciencia/?section=8\&edicao=26\&id=296, acesso em: 30/07/2020.

PILLA, Armando; QUADROS, Cynthia Boos de. Charge: Uma Leitura Orientada Pela Análise Do Discurso De Linha Francesa. In: Linguagens - Revista de Letras, Artes e Comunicação. Blumenau, v. 3, n. 3, p. 226-239, set./dez. 2009, disponível em: https://proxy.furb.br/ojs/index.php/linguagens/article/view/1497, acesso em: 30.06.2020.

ROMUALDO, Edson Carlos. Charge jornalística: intertextualidade e polifonia: estudo de charges da Folha de S. Paulo. Maringá - PR: EDUEM, 2000.

\title{
NOTAS
}

\author{
Diana Siqueira Liberatti \\ Mestranda no Programa de Pós-Graduação Interdisciplinar em Estudos da Condição Humana \\ Universidade Federal de São Carlos / Campus Sorocaba, Departamento de Ciências Humanas e Educação, Sorocaba, Brasil \\ diana.liberatti@estudante.ufscar.br \\ https://orcid.org/0000-0003-4559-153X
}

Endereço de correspondência do principal autor

Rua Maria da Glória Silva, 260, Jardim Escócia, CEP. 18.190-000, Araçoiaba da Serra, SP, Brasil.

AGRADECIMENTOS

Não se aplica

\section{CONTRIBUIÇÃO DE AUTORIA}

Márcio Antonio Gatti

Doutor em Linguística, Professor adjunto, Universidade Federal de São Carlos / Campus Sorocaba, Departamento de Ciências Humanas e Educação, Sorocaba, Brasil maggatti@ufscar.br

https://orcid.org/0000-0001-9902-2856 
Concepção e elaboração do manuscrito: L. S. Sobrenome, J. T. Sobrenome, A. P. Sobrenome

Coleta de dados: L. S. Sobrenome, J. T. Sobrenome, A. P. Sobrenome

Análise de dados: L. S. Sobrenome, J. T. Sobrenome

Discussão dos resultados: J. T. Sobrenome

Revisão e aprovação: A. P. Sobrenome

\section{CONJUNTO DE DADOS DE PESQUISA}

Todo o conjunto de dados que dá suporte aos resultados deste estudo foi publicado no próprio artigo.

\section{FINANCIAMENTO}

Não se aplica.

\section{CONSENTIMENTO DE USO DE IMAGEM}

Não se aplica.

\section{APROVAÇÃO DE COMITÊ DE ÉTICA EM PESQUISA}

Não se aplica.

\section{CONFLITO DE INTERESSES}

Não se aplica.

\section{LICENÇA DE USO}

Os autores cedem à Revista Internacional Interdisciplinar INTERthesis os direitos exclusivos de primeira publicação, com o trabalho simultaneamente licenciado sob a Licença Creative Commons Attribution (CC BY) 4.0 International. Estra licença permite que terceiros remixem, adaptem e criem a partir do trabalho publicado, atribuindo o devido crédito de autoria e publicação inicial neste periódico. Os autores têm autorização para assumir contratos adicionais separadamente, para distribuição não exclusiva da versão do trabalho publicada neste periódico (ex.: publicar em repositório institucional, em site pessoal, publicar uma tradução, ou como capítulo de livro), com reconhecimento de autoria e publicação inicial neste periódico.

\section{PUBLISHER}

Universidade Federal de Santa Catarina. Programa de Pós-graduação Interdisciplinar em Ciências Humanas. Publicação no Portal de Periódicos UFSC. As ideias expressadas neste artigo são de responsabilidade de seus autores, não representando, necessariamente, a opinião dos editores ou da universidade.

\section{EDITORES}

Javier Ignacio Vernal e Silmara Cimbalista

\section{HISTÓRICO}

Recebido em: 08-09-2021 - Aprovado em: 04-10-2021 - Publicado em: 25-10-2021 